\title{
Design characteristics, codes and standards of natural fibre composites
}

\begin{abstract}
The pursuit towards achieving sustainable construction worldwide has spurred a great effort in improving current practices in the building and construction industry. The high involvement in terms of research and application of environmentally friendly raw materials for the industry is one of the showcases of the effort made in achieving this goal. One of the most promising sources of raw material, which can highly contribute to improve the environmental performance of current building materials, is natural fibre composites (NFC). NFC is acknowledged as a renewable and recyclable material and can also offer advantages such as low cost and high material availability and, most importantly, has low energy and greenhouse gas emission implications during use. In this chapter the involvement of NFC for a sustainable construction process is explained with a focus on the design characteristics, codes and standards. An overview of NFC for sustainable construction is explained with examples on various building and construction product applications. Furthermore, a new proposed design model involving NFC laminate for shear strengthening of reinforced concrete (RC) beams is also included in this chapter. Finally, a case study on the applicability of the new design model is also demonstrated using kenaf fibre reinforced polymer (KFRP) composites. It is expected that the design model can serve as a reference to systematic and correct design practice for practitioners, involving the use of NFC in RC beams for building and construction applications.
\end{abstract}

Keywords: Design; Natural fibre composites; Reinforced concrete beam; Shear strengthening; Sustainable construction 